\title{
PESQUISA COM GRUPO FOCAL: CONTRIBUIÇÕES AO ESTUDO DAS REPRESENTAÇÕES SOCIAIS
} INVESTIGACIÓN CON GRUPO FOCAL: CONTRIBUCIONES AL ESTUDIO
DE LAS REPRESENTACIONES SOCIALES
RESEARCH WITH FOCAL GROUP: CONTRIBUTIONS TO THE STUDY ON
SOCIAL REPRESENTATION

http://dx.doi.org/10.1590/1807-03102016v28n3p433

\author{
Danielle Oliveira Nóbrega \\ Universidade Federal do Rio Grande do Norte, Natal/RN e Universidade Federal de Alagoas, Palmeira dos \\ Índios/AL, Brasil \\ Erika dos Reis Gusmão Andrade e Elda Silva do Nascimento Melo \\ Universidade Federal do Rio Grande do Norte, Natal/RN, Brasil
}

\section{RESUMO}

Este artigo é uma reflexão teórica, que objetiva discutir sobre o grupo focal enquanto aporte metodológico válido para pesquisas com a Teoria das Representações Sociais - TRS. Tem como argumento central a afirmação de que o grupo focal é uma técnica de produção de dados profícua em estudos que enfoquem o contexto grupal e os movimentos de constituição das representações sociais, uma vez que pode evidenciar tal processo e sua sociogênese. Para tanto, discute-se a TRS, enfatizando seu caráter psicossocial e sua base sociogenética e, em seguida, aborda-se a estratégia do grupo focal em pesquisas com a TRS. Conclui-se que o cenário de comunicações e interações proporcionado pelo grupo focal cria oportunidades de acesso às representações sociais e aos elementos e processos grupais que as constituem, favorecendo em especial investigações sobre suas características sociogenéticas.

Palavras-chave: Teoria das Representações Sociais; grupo focal; métodos de pesquisa.

\section{RESUMEN}

Este artículo es una reflexión teórica, que tiene como objetivo discutir el grupo focal como un método válido para investigaciones sobre la Teoría de las Representaciones Sociales - TRS. Su argumento central es la afirmación de que el grupo focal es una técnica de producción de datos fecunda en los estudios que se centran en el contexto del grupo y en el movimiento de constitución de las representaciones sociales, ya que demuestra este proceso y su socio génesis. Con tal objeto, se discute la TRS, su carácter psicosocial y su base socio genética y, después, se aborda la estrategia del grupo focal en la investigación con la TRS. Nuestras conclusiones describen que el escenario de las comunicaciones e interacciones proporcionadas por el grupo focal crea oportunidades de acceso a las representaciones y a los elementos y procesos grupales que las constituyen, favoreciendo particularmente las investigaciones sobre su característica socio genética.

Palabras clave: Teoría de las Representaciones Sociales; grupo focal; métodos de investigación.

\section{ABSTRACT}

This paper is a theoretical reflection, which aims to discuss the focus group as a valid methodological approach to research on the Theory of Social Representations - TSR. Its central argument is that the focus group is a profitable technique of data producing in studies that observe the group context and the movements of the constitution of social representations, because it can evidence this process and its socio genesis. For this purpose, we discuss the TRS, emphasizing its psychosocial character and its socio genetic basis and then, we discuss the strategy of the focus group in researches with TSR. We conclude that the scenario of communications and interactions provided by the focus group creates opportunities for access to social representations and to its elements and group processes that constitute them, which favors researches about their socio genetic characteristics, in particular.

Keywords: Theory of Social Representations; focal group; research methods. 


\section{Introdução}

Recentemente, a Teoria das Representações Sociais comemorou 50 anos de existência, marcados por uma fecunda produção de pesquisas científicas em diversos campos de saber. Isso se deve, em parte, por ser uma teoria com vitalidade, transversal e complexa (Jodelet, 2001), o que propicia a articulação de diferentes áreas de estudo, aponta para uma diversidade de problemáticas, requer o olhar a partir de múltiplas perspectivas e o estudo interconectado de elementos distintos.

Ao longo de seus 50 anos, observa-se que os caminhos da Teoria das Representações Sociais (doravante, TRS) são caracterizados por múltiplas trilhas metodológicas, que, de forma geral, são positivamente consideradas por estudiosos da teoria. Assim, um dos aspectos que se sobressaem na TRS é seu caráter plurimetodológico, permitindo explorar objetos distintos. Se, por um lado, tais condições aparentam conforto por ampliar as possibilidades de trabalho, por outro, implicam em rigor e critério nas escolhas metodológicas.

Camargo (2005) destaca a necessidade de utilização de vários métodos e de inovações metodológicas devido à complexidade das representações sociais, contudo, adverte que os pesquisadores envolvidos com a TRS não devem abandonar procedimentos sistemáticos e objetivos de observação e de análise de dados. Partindo dessa assertiva, o presente artigo insere-se na discussão a respeito das articulações teórico-metodológicas necessárias à realização de pesquisas coerentes com a TRS, abordando tais articulações a partir de uma estratégia metodológica específica: o grupo focal. Diante disso, seu objetivo é discutir o grupo focal enquanto instrumento de investigação profícuo em pesquisas na Teoria das Representações Sociais, destacando suas potencialidades, especialmente em trabalhos que enfoquem o caráter sociogenético das representações.

Esclarecemos que, para a realização deste texto, recorremos a uma pesquisa bibliográfica, realizada com base na literatura sobre representações sociais, disposta nos meios impresso e eletrônico. Adotou-se como critério para a seleção da literatura a presença de discussões que contribuíssem para articular a relação entre a TRS e o trabalho com grupo focal.

Buscamos, inicialmente, discutir a TRS, abordando o foco de Moscovici com a elaboração da teoria, suas bases epistemológicas, bem como aspectos das representações sociais pertinentes ao artigo em tela. Na segunda seção, tratamos do grupo focal, resgatando seu histórico, definições e procedimentos gerais. Também explicitamos as interlocuções do grupo focal e da TRS, ressaltando suas contribuições e possibilidades de trabalho. Na terceira seção, sinalizamos a possibilidade de empregar o grupo focal em investigações acerca das características sociogenéticas das representações sociais. Finalmente, nas considerações finais, afirmamos que as representações sociais, enquanto conhecimento forjado nos movimentos do grupo, têm nos grupos focais um relevante instrumento investigativo no que tange à oportunidade de captar tais representações, seus conteúdos e movimentos constitutivos, o que propicia particularmente investigações sobre as características que compõem sua sociogênese.

\section{A Teoria das Representações Sociais: o olhar para um conhecimento produzido nos movimentos dos grupos em seu cotidiano}

Quando Moscovici publicou, em 1961, A psicanálise, sua imagem e seu público (Moscovici, 1976/2012), obra que apresentou a Teoria das Representações Sociais, suas preocupações centravamse no estudo de um conhecimento comumente negligenciado na esfera das ciências clássicas: os saberes do senso comum. Seu foco direcionava-se, pois, para aqueles conhecimentos produzidos no cotidiano, nas relações entre os sujeitos em grupo e, nessa direção, buscava reafirmar o pensamento social, quer dizer, ratificar que há uma sociedade que pensa e que tal pensamento não pode ser considerado inferior ao científico.

Com a noção de representações sociais, Moscovici (1976/2012) oportunizou uma revisão radical no entendimento do senso comum. Superando concepções que impregnavam a ciência nesse período, ele se negou a concebê-lo como um saber irracional e ilógico. Com efeito, o senso comum é dotado de uma racionalidade própria e tem um papel importante no cotidiano, já que permeia e contribui na constituição de realidades sociais.

Wagner, Hayes e Palacios (2011) afirmam que o senso comum é o nosso reservatório de conhecimentos contextuais disponíveis de forma espontânea, que abarcam uma variedade de áreas e que possuem um papel importante na vida cotidiana. Neste sentido, entendemos a relevância de estudos sobre as representações sociais, enquanto conhecimentos do cotidiano, como forma de apreender elementos fundantes das sociedades que pensam e produzem esses saberes. 
Para compreender o caminho tomado por Moscovici na defesa da racionalidade das representações sociais, é preciso recorrer ao conceito de representações coletivas de Durkheim. Ao resgatar esse conceito, Moscovici debruçou-se sobre o trabalho do sociólogo acerca das práticas religiosas de tribos australianas, em que se observou a importância das representações coletivas partilhadas e transmitidas de geração em geração para o estabelecimento de uma realidade social (Moscovici, 2005).

O conceito de representação coletiva mantevese eclipsado nas ciências sociais, sendo questionado em aspectos distintos, como a cisão entre indivíduo e sociedade, na qual se sobressai uma visão dicotomizada de um social estático e independente das ações individuais (Alba, 2014). De fato, Wagner, Hayes e Palacios (2011) reconhecem que Moscovici fundamentou-se no trabalho de Durkheim sobre as representações coletivas, todavia, adaptou-as de modo a torná-las mais dinâmicas, aplicáveis à sociedade moderna e acessíveis à investigação psicossocial.

Nestes termos, em sua busca por um conceito que tratasse de uma sociedade pensante e, ao mesmo tempo, não incorresse em dicotomias e isolamentos, Moscovici buscou aliar componentes de determinadas perspectivas sociológicas e psicológicas, com o intuito de construir seu próprio conceito: as representações sociais. Assim, foi preciso retomar outras perspectivas teóricas como as de Lévy-Bruhl, Piaget e Freud em relação ao olhar para as representações.

Em específico, abordamos o trabalho de Piaget e sua psicologia cognitiva, pela contribuição nos estudos a respeito do desenvolvimento do pensamento infantil. Conforme Arruda (2002), a partir dos trabalhos piagetianos sobre tal pensamento em sua estrutura e configuração, evidencia-se que este se caracteriza por imagens e por recortes e colagens de fragmentos daquilo que a criança conhece de modo a formar uma configuração que abarque o que ela ainda desconhece. Moscovici busca, então, em Piaget elementos que respondam aos anseios quanto à gênese das representações da criança, o que destaca sua preocupação com uma perspectiva de compreensão do pensamento social que reposicione o indivíduo, alocando-o a um papel mais ativo do que aquele discutido por Durkheim.

Ao agregar, em seu trabalho, investigações em uma perspectiva cognitiva, que olha para o indivíduo de modo ativo, Moscovici complexifica e dinamiza a noção de representação e supera as representações coletivas de Durkheim. Nesse processo, o conceito de representações sociais localiza-se no cruzamento entre o indivíduo e a sociedade. De acordo com Alba (2014):
O conceito de representação social compreende um processo sociocognitivo específico, e não apenas uma ampla classe de ideias ou uma categoria demasiado geral que visa abranger toda forma de pensamento social. Ao reconhecer que as representações são, ao mesmo tempo, geradas e adquiridas, elas tornam-se mais dinâmicas e perdem seu caráter estático, fixo e pré-estabelecido que tinha o conceito original. (p. 528)

Essa proposição moscoviciana possibilitou a inscrição da TRS em uma perspectiva psicossocial da Psicologia Social, fornecendo subsídios para o rompimento de dicotomias nessa área, em que predominavam estudos parciais e míopes, que ora enfatizavam a dimensão social em detrimento do indivíduo, ora abarcavam o individual, negligenciando o social (Guareschi, 2007). Em oposição, Moscovici postulou sobre a indissociabilidade entre sujeito e objeto, interno e externo, psíquico e social, concebendo as relações entre esses elementos como circulares, dialéticas e complexas.

Tais entendimentos não permitem que olvidemos que os estudos em representações sociais devem partir de uma análise psicossocial, em que é preciso considerar que a representação social tem necessariamente uma gênese social e um caráter compartilhado, sendo constituída e constituindo comunicações. Isto é, tratase de um conhecimento produzido em um contexto grupal que possibilita a criação de uma realidade partilhada socialmente.

Isto posto, em seus escritos, Wagner (2000) propõe o olhar para a sociogênese desse conhecimento, reunindo características e critérios que sinalizam a importância de acessar ao grupo que a produziu, em seus processos de interação e de comunicação. É seguindo, pois, tal proposta que consideramos pertinente às nossas reflexões quando o autor explica que as representações sociais são um produto e um processo de comunicação, o que indica que elas são constituintes e constitutivas de realidades partilhadas.

Além disso, Wagner observa que, por serem ao mesmo tempo geradas e adquiridas, as representações sociais possuem um traço dinâmico que está presente nas comunicações e que se vincula a uma diversidade significativa de saberes com racionalidades distintas que atravessam esses processos. Nessa altura, recorremos à Arruda (2014) que explica que as representações sociais têm no convívio entre lógicas diversas uma amostra dessa dinâmica.

Isso nos conduz ao conceito de polifasia cognitiva, que diz respeito às possibilidades de usos diversificados - pelos grupos e/ou pelos sujeitos - de 
pensamentos e conhecimentos com racionalidades distintas, como o científico, senso comum, religioso, entre outros. Como argumenta Jovchelovitch (2014), a hipótese da polifasia cognitiva ensina que não é preciso uma separação radical dos saberes ou a eliminação de suas diferenças. Na verdade, o contexto de constituição de representações sociais não corresponde a um cenário homogêneo, trata-se mais de um espaço dinâmico e heterogêneo, marcado por embates e tensões entre saberes.

Em síntese, podemos salientar que as representações sociais são conhecimentos acerca de fenômenos, eventos ou objetos sociais construídos no cotidiano por um grupo social, sendo atravessados pelas condições sociais, históricas, culturais concernentes a esse grupo. Tais conhecimentos são forjados nas comunicações e interações grupais e se caracterizam pela dinamicidade e diversidade de saberes, que convergem ou divergem diante das próprias relações grupais.

Desse modo, não há representação social sem um grupo que se relaciona com uma determinada realidade a ser representada. Considerando que as representações se configuram enquanto produto e processo de relações grupais, é preciso conhecer o fenômeno passível de representação, bem como o grupo que o representa. Conhecer esse grupo, suas necessidades, crenças, valores e relações compõe caminhos pertinentes a pesquisas em representações sociais.

Nesta perspectiva, estudos que enfatizem o processo constitutivo das representações sociais e seu caráter sociogenético podem se beneficiar de um conjunto de metodologias que buscam colocar em evidência o movimento de constituição das representações sociais e inter-relacionar diversos componentes dessa formação no contexto do grupo que as movimenta. Dentre os instrumentos de investigação que buscam atender a tal demanda, destacamos o grupo focal, que será discutido na próxima seção.

\section{Grupo focal: o olhar para os movimentos dos grupos em suas articulações com as representações sociais}

Reconhecemos que, no campo da pesquisa em representações sociais, os pesquisadores têm feito uso extensivo do potencial do grupo focal (Jovchelovitch, 2004; Oliveira \& Werba, 1998), de maneira que este se configura como uma estratégia de pesquisa tradicional na TRS. Em geral, há trabalhos que visam à identificação de representações sociais, outros enfocam seus processos comunicacionais e interacionais, entre outros (Galinkin, Almeida, \& Anchieta, 2012; Ribeiro \& Cruz, 2013; Silva \& Silva, 2012; Silva, Trindade, \& Silva, 2012; Stenzel \& Guareschi, 2002). Tais estudos são possíveis pela consideração básica de que o grupo focal favorece a interação e a comunicação grupal, permitindo a emergência das representações sociais em seus conteúdos e movimentos constitutivos. Ademais, Banchs (2005, p. 401) defende que os grupos focais devem ser utilizados como uma estratégia para estudos nesse campo por permitirem "por un lado, conocer los contenidos discursivos en torno a los cuales se estructuran las representaciones de un objeto, y por el otro, estudiar los procesos sociales de construción de essas representaciones".

Ressalta-se que a técnica não é exclusividade de investigações em representações sociais. Em seu histórico, verifica-se que ela surge para responder demandas de trabalho distintas. É por volta da década de 1940 que os grupos focais foram criados, sendo utilizados por Paul Lazarsfeld, Robert Merton e colegas em Columbia, Estados Unidos, visando investigar as reações às propagandas e transmissões de rádio durante a Segunda Guerra Mundial. Denominadas como entrevistas focais e aliadas aos métodos quantitativos, nesses trabalhos, há pouca diferenciação entre as entrevistas individuais e grupais, embora já se reconhecesse seu potencial na produção de dados (Barbour, 2008).

Segundo Barbour (2008), após a guerra, os grupos focais tornaram-se importantes instrumentos de pesquisa voltados ao marketing, à emissão de mensagens, à opinião pública e à resolução de problemas organizacionais. Contudo, com o avançar do século XX, eles não se restringiram a esses campos, ainda conforme Barbour (2008), os grupos focais foram utilizados em trabalhos de desenvolvimento comunitário e abordagens participativas e em serviços de saúde e pesquisas em ciências sociais.

Tal diversidade contribuiu para sua disseminação e diversificação de áreas e por ganhar uma perspectiva mais acadêmica e crítica. É o caso das aproximações entre os grupos focais e a sociologia e a psicologia social crítica que, com estudos em representações sociais, análise do discurso e produção de sentidos, também forneceram referenciais para trabalhos com essa técnica (Kind, 2004). Atentamos que a forma de analisar os dados produzidos aqui é bem diferente daquela utilizada nos primórdios da técnica, em que se privilegiava uma análise quantitativa. Kind (2004) explica que, com as pesquisas em sociologia e psicologia social crítica, foi sendo sublinhado um olhar comumente psicossocial, com referenciais teóricos específicos dessas áreas. 
O trabalho em grupo seria a característica básica para definir grupo focal, entretanto, isso não é suficiente para dirimir as confusões nas concepções sobre essa técnica. Barbour (2008) explicita as dificuldades quanto à definição e ao uso de termos como entrevistas de grupo, entrevista de grupo focal e discussões em grupo focal. Para a autora, há quem aproxime a técnica de uma compreensão de entrevista de grupo focal, em que as perguntas elaboradas pelo pesquisador são respondidas coletivamente, sem considerar, nesse caso, o processo de criação do consenso pela interação em uma discussão de grupo focal.

Gondim (2002) fornece mais elementos para esse debate ao estabelecer que a distinção reside no papel do entrevistador e no tipo de abordagem. No caso da entrevista grupal, o entrevistador possui um papel mais diretivo por sua relação ser com cada membro em si. Eles ouvem a opinião de cada um e comparam suas respostas, assim, seu nível de análise é o indivíduo no grupo. Já no grupo focal, o moderador é um facilitador do processo de discussão e sua ênfase repousa nos processos psicossociais emergentes. Aqui, a unidade de análise é o próprio grupo.

De fato, é preciso ir além do mero entendimento de entrevista em grupo e destacar aspectos fundantes que emergem durante o emprego da técnica e que só são possíveis de emergir devido a sua qualidade de discussão grupal. Morgan (1996, p. 130) define grupo focal como "a research technique that collects data through group interaction on a topic determined by the researcher". Nessa definição, torna-se evidente que não há como desvincular da técnica seu olhar para o grupo não apenas como um somatório de pessoas que estão ocasionalmente reunidas, mas como um conjunto que interage, comunica, expõe dissensos e consensos e são mediadas pelo pesquisador, que abandona uma postura pretensamente neutra e assume uma participação ativa na produção dos dados.

A interação em um grupo focal é realçada por Kitzinger (1994), quando destaca seu uso como dado de pesquisa. Dentre suas vantagens, mencionamos o fato de o grupo focal fornecer insights sobre a operação de processos sociais/grupo na articulação de conhecimento (Kitzinger, 1994), o que é deveras relevante em pesquisas que investigam a constituição das representações sociais.

Em sua definição, Kind (2004) também enfatiza a interação grupal como elemento que produz dados e insights que raramente seriam conseguidos em situações fora do grupo. Considera, pois, o processo grupal, concebendo-o mais que a soma de opiniões, sentimentos e pontos de vista individuais e chamando a atenção para sua adequação a pesquisas de caráter qualitativo.
Banchs defende que, dentre as técnicas qualitativas de coleta de dados, o grupo focal é a que mais se aproxima de uma conversação espontânea. Em suas palavras, "El procedimiento consiste en proponer al grupo de personas reunido un tema de discusión. No se trata de realizar preguntas para que el grupo responda sino de estimular la conversación entre ellos en torno al tópico que interesa investigar" (Banchs, 2005, p. 410). Exatamente por essa aproximação, com tal técnica é possível o aprofundamento de estudos cujo enfoque se localize naqueles aspectos discutidos na seção anterior: a comunicação, o caráter compartilhado e dinâmico das representações sociais.

Grupos focais são comunicação, afirma Marková (2004), que explicita ainda que esse método permite que os participantes falem espontaneamente sobre um tópico. Para a autora, os grupos focais oferecem uma oportunidade de desenvolver uma pesquisa com métodos dinâmicos, baseados na comunicação, linguagem e pensamento. Além disso, abrem espaço para pesquisas acerca da formação e da transformação de representações sociais: "En tant que méthode de recherche, les focus groups peuvent nous donner accès à la formation et aux transformations des représentations sociales, des croyances, des connaissances et des idéologies circulant dans les sociétés" (Marková, 2004, pp. 235-236).

Em outro artigo, Kitzinger, Marková e Kalampalikis (2004) também centralizam na comunicação a importância do grupo focal para a TRS, uma vez que ela é o coração das representações sociais. Os autores resgatam Moscovici ao retomar que a comunicação proporciona a formação de ideias, crenças e opiniões, o que se sobressai no grupo focal. Neste, os participantes conversam sobre um determinado tópico em geral proposto pelo mediador, emitem opiniões, concordam, discordam, interpelam-se, reavaliam ideias, confundem-se, enfim, comunicam-se e, nesse movimento, evidenciam não somente suas representações sociais, como também os processos que permitem sua constituição e emergência.

Ademais, determinados estudos em representações sociais interessam-se pelos processos de formação de conhecimentos que se referem aos mecanismos de objetivação e de ancoragem. Ambos não podem ser compreendidos unicamente a partir da dimensão individual ou coletiva separadamente. Ao resgatarmos brevemente, na seção anterior, como Moscovici elaborou a TRS, ficou evidenciada sua preocupação em consolidar uma perspectiva psicossocial, visando evitar que os olhares individual ou coletivo isolados deixem resvalar o fenômeno representacional. Então, a compreensão dos 
mecanismos de objetivação e de ancoragem deve abranger um olhar psicossocial, que permita vislumbrar como determinadas ideias, conceitos, sentimentos, crenças, dentre outros, são compartilhados em um grupo, como se confrontam ou se conformam e como nesse movimento as representações sociais são forjadas.

Diante disso, o grupo focal pode ser uma estratégia que dispõe desse olhar psicossocial. Por ser um procedimento caracterizado pela discussão em grupo, é possível ao pesquisador ouvir vários sujeitos ao mesmo tempo e observar características do processo grupal (Kind, 2004). Aqui, concebe-se que as falas desses sujeitos são carregadas de elementos simbólicos, cognitivos, afetivos, atitudinais e sociais. Tais falas são expostas no grupo, acolhidas ou não, e intercambiadas. São material para comunicação e para formação de representações sociais, por isso, não devem ser analisadas de modo individualizado, mas em uma perspectiva de produção grupal.

Em acordo com Silva, Trindade e Silva (2012), essa técnica oportuniza a visualização da construção compartilhada do conhecimento, quer dizer, permite em um ambiente controlado o acesso às representações sociais. Os autores compreendem que, nesse contexto grupal, os sujeitos explicitam as representações como uma elaboração de todos, em um processo que é dinâmico e que envolve consensos e dissensos sobre um objeto.

O grupo focal também é profícuo em pesquisas dedicadas aos estudos acerca da polifasia cognitiva na TRS. Retomamos o argumento de Jovchelovitch (2014, p. 231), que explica que não há uma separação radical entre os saberes, posto que a polifasia cognitiva implica em diálogo com a diferença: "é nessa diferença, e nas continuidades e descontinuidades que ela sustenta que reside o potencial de todo saber humano".

Nesse sentido, o grupo focal, por provocar a conversação entre os participantes de uma pesquisa, tona-se um espaço propício para a circulação e emergência de saberes com racionalidades distintas. Desse modo, os participantes do grupo, diante de um tópico de discussão, comunicam-se e assumem posicionamentos, norteados por determinados saberes que podem ser colocados em uma posição de conflito com outros. Esses movimentos mostram a polifasia cognitiva presente na constituição dos conhecimentos pelo grupo.

Perante as possibilidades aqui apresentadas, pesquisas com grupo focal requerem a sistematização de procedimentos metodológicos que propiciem interações e comunicações da forma mais espontânea possível. Nessa direção, Gondim (2002) esclarece que o ponto de partida é a clareza de propósito com os grupos focais, ou seja, qual o objetivo com a técnica. Isso influenciará as decisões seguintes, as quais buscarão atender às expectativas com o procedimento.

Sendo uma estratégia metodológica, o grupo focal pode ser usado sozinho ou em combinação com outras técnicas de pesquisa. É o caso da combinação com entrevistas individuais, que podem ser empregadas antes ou depois dos grupos, a depender dos propósitos do trabalho. Em diversos estudos, o grupo focal surge associado à entrevista (Araldi, Njaine, Oliveira, \& Ghizoni, 2012; Fagundes, Crespo, \& Guareschi, 2013), à Técnica de Associação Livre de Palavras (Ribeiro \& Cruz, 2013; Rodrigues, Lima, \& Roncalli, 2008), aos questionários (Rodrigues et al., 2008), à produção de desenhos (Ribeiro \& Cruz, 2013), às observações (Araldi et al., 2012; Possamai \& Guareschi, 2007), dentre outros. As razões para tais associações variam conforme cada trabalho, porém, pode-se apontar a demanda por complementaridade entre técnicas, visando abranger diferentes dimensões da representação social em estudo.

As discussões realizadas até agora elucidaram elementos importantes do encontro entre a TRS e o grupo focal, visto que este último oportuniza a interação, a comunicação e o olhar psicossocial e a dinamicidade tão caros à primeira. A seguir, exploraremos a proposição de que o grupo focal pode ser empregado em pesquisas que busquem esclarecer a sociogênese de uma representação social.

\section{Movimentos do grupo focal: o olhar para a sociogênese das representações sociais}

Retomando Wagner (2000), a representação social enquanto produto não pode ser concebida separada de sua condição sociogenética sob a qual foi formada. Destarte, cogitamos que é preciso responder questões que contribuam no delineamento sociogenético da representação, tais como: de que modo o grupo se comunica? Quem compõe esse grupo? Que práticas são construídas acerca desse objeto? Como esse grupo se identifica e se relaciona com o objeto? Como os participantes expressam seu pertencimento ao grupo? Que relações podem ser tecidas entre o conhecimento público e o privado? Essas questões reportam às características sociogenéticas e permitem aprofundar o cenário em que as representações sociais são elaboradas.

Quando nos perguntamos como o grupo se comunica e quem compõe esse grupo, evidenciamos a 
comunicação e o grupo reflexivo como características presentes na constituição da representação social. É na comunicação em que se envolvem os grupos reflexivos que as representações sociais são forjadas e seu conteúdo se revela. Daí, a relevância de favorecer esses espaços, já que, em consonância com Wagner (2000), o processo de constituição das representações movimenta-se a partir das convergências e divergências na comunicação e das necessidades práticas. Assim, o delineamento do grupo deve propiciar a circulação dos discursos sociais, os quais incluem a comunicação de pontos de vista compartilhados e divergentes.

Outra característica sociogenética que pode se destacar em um grupo focal é o fato de as representações sociais envolverem uma prática e uma construção social. Segundo Wagner (2000), a TRS é uma teoria sobre a construção social que ocorre quando os membros de um grupo agem no sistema de representação e criam o objeto representado, dotandolhe de significado e realidade. Nessa perspectiva, os grupos focais assumem um papel relevante na medida em que explicitam a interação, que é base nesse processo de construção social. Assim, os grupos devem ser considerados não só em função do que se diz, mas também de acordo com estruturas interativas que regulam o conteúdo (Jovchelovitch, 2004). Nas palavras de Wagner (2000, p. 11), "A interação entre as pessoas expressa e confirma suas crenças subjacentes; de fato, a representação social é sempre uma unidade do que as pessoas pensam e do modo como fazem".

Também se deve responder às formas como esse grupo se identifica e se relaciona com o objeto, o que nos conduz à característica associada à identidade social e evidência do conhecimento. Ao longo dos encontros de um grupo focal, a forma de discussão de um tópico, os elementos ressaltados, os conteúdos silenciados, as contradições, etc, contribuem para desenvolvermos esse aspecto sociogenético. Wagner (2000) explica que as representações sociais expõem o estilo de pensamento dos membros do grupo que as construiu. A identidade social envolve o conhecimento sobre qual grupo alguém pertence, bem como o surgimento da experiência comum do conhecimento, senso comum e padrões justificatórios. Tal experiência permite aos membros do grupo localizarem-se dentro de um espaço discursivo comum, além do que a identidade social é disposta como uma fonte de evidência que confere verdade às crenças.

Uma quarta característica sociogenética que pode ser explorada em um grupo focal é a presença do grupo no indivíduo. Silva e Silva (2012) ressaltam que os atores do grupo focal não falam de modo isolado, mas representam seus grupos de pertença. Nesta direção, abordamos novamente os escritos de Wagner (2000), que explicitam que uma das características sociogenéticas das representações sociais corresponde ao entendimento de que o grupo está no indivíduo, ou seja, as representações pronunciadas pelos indivíduos no grupo contêm metainformações sobre suas identificações grupais. O autor chama essa metainformação de holomorfia (holos $=$ todo; morphé $=$ forma). Trata-se de uma classe de características das representações sociais que são resultantes diretamente da premissa de que estas são elaboradas no discurso público de um grupo reflexivo e pensante.

Por fim, uma última questão refere-se às relações que podem ser tecidas entre o conhecimento público e o privado. Wagner (2000) observa que, além do conhecimento público, há o conhecimento privado, sendo este último chamado de "idiomórfico" (do grego - idios = próprio; morphé = forma). Trata-se de "um sistema de conhecimento que justifica experiências e comportamentos privados, independentemente de outras pessoas, que pudessem validar consensualmente suas teorias, e também independentemente de qualquer grupo reflexivo, onde suas teorias fossem aceitas como uma representação social" (Wagner, 2000, p. 16).

$\mathrm{O}$ autor pondera que, apesar de serem pessoais, tais conhecimentos sempre serão baseados, embutidos e associados a um conhecimento social e cultural prévio. Com efeito, em discussões do grupo focal, essa característica também pode emergir na medida em que se verifica, na interação grupal, ideias individuais, não compartilhadas. Como expõe Marková (2004), esse método propicia que os membros do grupo falem espontaneamente tanto de um ponto de vista pessoal como público.

\section{Considerações finais}

A Teoria das Representações Sociais chega ao seu cinquentenário preservando $o$ caráter plurimetodológico e, ao mesmo tempo, impondo a exploração de dimensões teóricas e metodológicas diversas. Diante dessa provocação, visamos aqui discutir o grupo focal enquanto uma estratégia de investigação na TRS, buscando articular tal técnica com os aspectos que compõem a teoria, como seus movimentos constitutivos e seu caráter sociogenético.

Dentre os aspectos das representações sociais, destacamos ao longo do texto: a dimensão psicossocial, que enfatiza a indissociabilidade entre sujeito e objeto, interno e externo, psíquico e social; seu caráter compartilhado, que reafirma a importância da interação social e da comunicação na constituição 
de representações; sua dinamicidade, que sinaliza a polifasia cognitiva, com a heterogeneidade de saberes que concorrem na produção de representações sociais; e a sociogênese, que, a partir de suas características, põe em relevo a origem social impressa nas representações sociais. Essas características permitem localizar as representações enquanto um conhecimento complexo, múltiplo, dinâmico e com objetivos práticos, concernentes ao grupo a que se vincula.

Durante um encontro de grupo focal, é possível observar os movimentos grupais fundamentais na constituição das representações sociais. Assim, o grupo interage e se comunica e, nesses movimentos, podem ser visualizadas a intersubjetividade, as relações entre sujeitos, objetos e o mundo social, além das múltiplas relações entre saberes distintos.

Indo além da identificação, Jovchelovitch (2004) argumenta que, com o grupo focal, pode-se compreender a gênese das representações sociais e como elas funcionam na sociedade. Dessa forma, é possível identificar sua lógica de produção e como esta lógica está vinculada a identidades, interesses e projetos específicos na sociedade. Nesta direção, acrescentamos que, por se aproximar de uma conversação cotidiana, o grupo focal possibilita acessar aos contextos de produção de sentidos e de formação de uma representação.

Finalmente, a sociogênese da representação social também é favorecida no grupo focal, uma vez que é possível ainda perceber os movimentos dos sujeitos sociais em situações controladas: como interagem e se comunicam, suas construções acerca de um tema, concordâncias e discordâncias, identificações e marcas de pertencimento, como são as negociações e trocas de experiências, etc. Esses são elementos centrais para compor o quadro das representações sociais: para além do seu conteúdo, busca-se o contexto em que se formam e se desenvolvem e as dimensões sóciohistórica e cultural que as envolvem e demarcam.

\section{Referências}

Alba, M. (2014). Representações sociais e memória coletiva: uma releitura. In A. M. O. Almeida, M. F. S. Santos, \& Z. A. Trindade (Orgs.), Teoria das representações sociais: 50 anos (pp. 519-571). Brasília, DF: Technopolitik.

Araldi, J. C., Njaine, K., Oliveira, M. C., \& Ghizoni, A. C. (2012). Representações sociais de professores sobre o uso abusivo de álcool e outras drogas na adolescência: repercussões nas ações de prevenção na escola. Interface - Comunicação, Saúde, Educação, 16(40), 135-148. Acesso em 02 de julho, 2014, em http://www.scielo.br/scielo.php?script=sci arttext\&pid=S1414-32832012000100011\&lng=pt\&tlng=pt

Arruda, A. (2002). Teoria das representações sociais e teorias de gênero. Cadernos de Pesquisa, 117, 127-
147. Acesso em 24 de fevereiro, 2016, em http://www. scielo.br/scielo.php?script $=$ sci arttext\&pid $=\mathrm{S} 0100$ $15742002000300007 \& \operatorname{lng}=$ pt\&tlng $=$ pt

Arruda, A. (2014). Representações sociais: dinâmicas e redes. In A. M. O. Almeida, M. F. S. Santos, \& Z. A. Trindade (Orgs.), Teoria das representações sociais: 50 anos (pp. 441489). Brasília, DF: Technopolitik.

Banchs, M. A. (2005). Representaciones sociales en proceso: su análises através de grupos focales. In A. P. Moreira, B. V. Camargo, J. C. Jesuíno, \& S. M. Nóbrega (Orgs.), Perspectivas teórico-metodológicas em representações sociais (pp. 401-423). João Pessoa: UFPB/Editora Universitária.

Barbour, R. (2008). Grupos focais. Porto Alegre: Artmed.

Camargo, B. V. (2005). Introdução. In A. P. Moreira, B. V. Camargo, J. C. Jesuíno, \& S. M. Nóbrega(Orgs.), Perspectivas teórico-metodológicas em representações sociais (pp. 1924). João Pessoa: UFPB/Editora Universitária.

Fagundes, C. M., Crespo, A. R., \& Guareschi, P. A. (2013). Violencia psicológica y asedio moral vertical ascendiente en dos escuelas públicas de Porto Alegre, Brasil. Salud trab. (Maracay), 21(2), 129-140. Acesso em 21 de junho, 2015, em http://www.scielo.org.ve/pdf/st/v21n2/art03.pdf

Galinkin, A. L., Almeida, A. M. O., \& Anchieta, V. C. C. (2012). Representações sociais de professores e policiais sobre juventude e violência. Paidéia, 22(53), 365-374. Acesso em 02 de julho, 2014, em http://www. scielo.br/scielo.php?script $=$ sci_arttext\&pid $=\mathrm{S} 0103$ $\underline{863 X 2012000300008 \& \operatorname{lng}=\text { pt\&tlng }=\text { pt. } \% 2010}$

Gondim, S. M. G. (2002). Grupos focais como técnica de investigação qualitativa: desafios metodológicos. Paidéia, 12(24), 149-161. Acesso em 02 de julho, 2014, em http:// www.scielo.br/scielo.php? script $=$ sci_arttext\&pid $=$ S0103$\underline{863 X 2002000300004 \& \operatorname{lng}=p t \& t \operatorname{lng}=\text { pt. }}$

Guareschi, P. A. (2007). Psicologia Social e Representações Sociais: avanços e novas articulações. In M. V. Veronese \& P. A. Guareschi (Orgs.), Psicologia do cotidiano: representações sociais em ação (pp. 17-40). Petrópolis, RJ: Vozes.

Jodelet, D. (2001). Representações sociais: um domínio em expansão. In As representações sociais (pp. 17-44). Rio de Janeiro: EdUERJ.

Jovchelovitch, S. (2004). Contextualiser les focus groups: comprendre les groupes et les cultures dans la recherche sur les représentations. Bulletin de Psychologie, 57(3), 245-252. Acesso em 21 de junho, 2015, em http://www.bulletindepsychologie.net/vente/ Les $\% 20$ groupes $\% 20$ centres $\% 20$ (focus $\% 20$ groups). pdf?PHPSESSID=b25ede9142c18b6d624bf119c11f71bd

Jovchelovitch, S. (2014). Representações sociais e polifasia cognitiva: notas sobre a pluralidade e sabedoria da razão em psicanálise, sua imagem e seu público. In A. M. O. Almeida, M. F. S. Santos, \& Z. A. Trindade (Orgs.), Teoria das representações sociais: 50 anos (pp. 211-236). Brasília, DF: Technopolitik.

Kind, L. (2004). Notas para o trabalho com a técnica de grupos focais. Psicologia em Revista, 10(15), 124-136. Acesso em 02 de julho, 2014, em http://www.pucminas.br/imagedb/ documento/DOC_DSC_NOME_ARQUI20041213115340. pdf.

Kitzinger, J. (1994). The methodology of focus groups: the importance of interaction between research participants. Sociology of Health and illness, 16(1), 103-121. Acesso 
em 21 de junho, 2015, em http://onlinelibrary.wiley.com/ doi/10.1111/1467-9566.ep11347023/pdf

Kitzinger, J., Marková, I., \& Kalampalikis, N. (2004). Qu'est-ce que les focus groups? Bulletin de Psychologie, 57(3), 237-243. Acesso em 21 de junho, 2015, em http://www.bulletindepsychologie.net/vente/Les $\% 20$ groupes $\% 20$ centres $\% 20 \% 28$ focus $\% 20$ groups $\% 29$. pdf?PHPSESSID=b25ede9142c18b6d624bf119c11f71bd

Marková, I. (2004). Langage et communication en psychologie sociale: dialoguer dans les focus groups. Bulletin de Psychologie, 57(3), 231-236. Acesso em 21 de junho, 2015, em http://www.bulletindepsychologie.net/vente/ Les $\% 20$ groupes $\% 20$ centres $\% 20 \% 28$ focus $\% 20$ groups $\% 29$. pdf?PHPSESSID=b25ede9142c18b6d624bf119c11f71bd

Morgan, D. (1996). Focus Groups. Annual Review of Sociology, 22, 129-152. Acesso em 02 de julho, 2014, em http:// digitalvillage.org.uk/docs/wp-content/uploads/2009/02/ morgan_d_1_1996 focus groups annual review of sociology.pdf

Moscovici, S. (2005). Representações sociais: investigações em psicologia social. Petrópolis, RJ: Vozes.

Moscovici, S. (2012). A psicanálise, sua imagem e seu público. Petrópolis, RJ: Vozes. (Original publicado em 1976)

Oliveira, F. O., Werba, G. C. (1998). Representações sociais. In M. G. C. Jacques, M. N. Strey, N. M. G. Bernades, P. A. Guareschi, S. A. Carlos, \& T. M. G. Fonseca (Orgs.), Psicologia social contemporânea: livro-texto (pp. 104-117). Petrópolis, RJ: Vozes.

Possamai, H. \& Guareschi, P. A. (2007). Minha culpa, meu destino: representações sociais dos acidentes de trabalho. In M. V. Veronese \& P. A. Guareschi (Orgs.), Psicologia do cotidiano: representações sociais em ação (pp. 225-246). Petrópolis, RJ: Vozes.

Ribeiro, F. S. \& Cruz, F. M. L. (2013). Representações sociais de família por crianças na cidade de Recife. Psicologia \& Sociedade, 25(3), 612-622.

Rodrigues, M. P., Lima, K. C., \& Roncalli, A. G. (2008). A representação social do cuidado no programa saúde da família na cidade de Natal. Ciência \& Saúde Coletiva, 13(1), 71-82.

Silva, P. B. \& Silva, P. (2012). Representações sociais de estudantes universitários sobre cotas na universidade. Fractal: Revista de Psicologia, 24(3), 525-542.

Silva, P. O. M., Trindade, Z. A., \& Silva, A. (2012). As representações sociais de conjugalidade entre casais recasados. Estudos de Psicologia, 17(3), 435-443. Acesso em 02 de julho, 2014, em http://www.scielo.br/scielo. php? script $=$ sci arttext\&pid $=$ S1413-294X2012000300012\& $\underline{\operatorname{lng}=\mathrm{pt} \& \mathrm{t} \operatorname{lng}=\mathrm{pt}}$
Stenzel, L. M. \& Guareschi, P. A. (2002). A dialética obesidade/ magreza: um estudo em representações sociais com adolescentes. Revista de Ciências Humanas, 1(n. spe.), 183194. Acesso em 21 de junho, 2015, em https://periodicos. ufsc.br/index.php/revistacfh/article/download/25845/22630

Wagner, W. (2000). Sócio-gênese e características das representações sociais. In A. P. Moreira \& D. C. Oliveira (Orgs.), Estudos interdisciplinares de representação social (pp. 03-25). Goiânia: AB Editora.

Wagner, W., Hayes, N., \& Palacios, F. F. (Eds.). (2011). El discurso de lo cotidiano y el sentido común: la teoria de las representaciones sociales. México: Anthropos.

Submissão em: 25/07/2015

Revisão em: 14/02/2016

Aceite em: 14/03/2016

Danielle Oliveira Nóbrega é professora de Psicologia da Universidade Federal de Alagoas/Unidade Educacional de Palmeira dos Índios. Doutoranda do Programa de Pósgraduação em Educação da Universidade Federal do Rio Grande do Norte. Endereço: Universidade Federal de Alagoas. Rua Sonho Verde S/N, Bairro Eucalipto. CEP 57.076-100. Palmeira dos Índios/AL, Brasil. E-mail: dani.nobrega@gmail.com

Erika dos Reis Gusmão Andrade é doutora em Educação pela Universidade Federal do Rio Grande do Norte. Professora do Departamento de Fundamentos e Políticas da Educação e do Programa de Pós-graduação em Educação da Universidade Federal do Rio Grande do Norte, na Linha de Pesquisa Práticas Pedagógicas e Currículo. E-mail: ergandrade@gmail.com

Elda Silva do Nascimento Melo é professora com Pósdoutoramento na Universidade de Valencia/Espanha; lotada no Departamento de Práticas Educacionais e Currículo e credenciada ao Programa de Pós-graduação em Educação

do Centro de Educação da Universidade Federal do Rio Grande do Norte; participa de grupos de pesquisa na área de Educação e coordena projetos envolvendo temas como a Formação Docente, Teoria das Representações Sociais e Ensino de Sociologia. Ministra as disciplinas de Estágio Supervisionado no curso Ciências Sociais e atua como avaliadora de cursos do Instituto Nacional de Estudos e Pesquisas Educacionais Anísio Teixeira - INEP. E-mail: eldamelo@ufrnet.br 